\title{
Are E-learning Apps Replacing the Classroom Learning among Dental Students? A Questionnaire Survey
}

\author{
Prabhu Subramani ${ }^{1}$, Mageswari $\mathrm{G}^{2}$, Kamalini $\mathrm{N}^{3}$, Muthavi $\mathrm{M}^{4}$
}

\begin{abstract}
Aim: The coronavirus disease-2019 (COVID-19) pandemic had brought a paradigm shift in education systems all over the world; dental education is no exception to it. This study aimed to determine how dental students perceive e-learning as having an influence on dental education.

Materials and methods: A cross-sectional descriptive study was conducted among $N=160$ students of Asan Memorial Dental College and Hospital. Self-administrated validated questionnaire consisting of questions about demographic profile, attitude, knowledge, and practice toward e-learning methodologies was assessed.

Results: Of $N=160$ students, $n=74(46.3 \%)$ were preclinical students and $n=86(53.8 \%)$ were clinical students. Of the preclinical students, $n=41(25.6 \%)$ preferred e-learning and $n=71$ (44.4\%) clinical students did $(p<0.05) . N=15(9.35 \%)$ of preclinical students and $n=44(27.5 \%)$ of clinical students surveyed indicated that the knowledge gained could be applied practically. $N=23$ (14.37\%) of preclinical students and $n=39(24.3 \%)$ of clinical students felt the e-learning system will be a success in the future.

Conclusion: E-learning apps are more beneficial for dental students than traditional methods of learning. The future of dental education will be made up of a combination of physical classes and online classes, which is known as blended learning.

Keywords: Dental education, Dental students, E-learning.

Journal of Scientific Dentistry (2021): 10.5005/jp-journals-10083-1008
\end{abstract}

\section{INTRODUCTION}

Education has undergone a substantial change in the past decade. An innovative education system has emerged, whereby students can learn without lecturers and can study from anywhere irrespective of location. While studies have been conducted over the last 10 years, it has found its place now in the field of dentistry because of a global pandemic. ${ }^{1}$ In addition to traditional instructional materials (audio, video, and text), these systems can also be used to integrate e-mail, live chat sessions, online discussions, forums, quizzes, and assignments. Using this type of system, instructors and students can communicate at the same time (synchronously) or at different times (asynchronously). ${ }^{2}$

The shift from traditional classrooms to e-learning is not immediate, and users need time to get used to it. In the e-learning environment, learning experience (e.g., the length of learning time) could play an important role in improving learning efficiency. Because of the fact that user attitudes and beliefs change over time, determining the determinants of e-learning persistence might not be the same for user with different levels of e-learning experience. ${ }^{3}$

Currently, the e-learning systems available on the market focus on technical devices, rather than supporting the learning process. ${ }^{4}$ As a result of e-learning, learners have the opportunity to interact with one another through discussion boards. This enables e-learning to remove barriers that could facilitate participation such as a fear of contact. In addition to motivating students to interact, e-learning makes communication easier and strengthens their relationships, which in turn sustain learning. ${ }^{5}$

In many professional education environments, such as dental schools, courses are team-taught, and lecturers and lecture styles differ greatly. As a dental educator, time, content, and depth of the curriculum are significant issues, compared with the expectations

\footnotetext{
${ }^{1-4}$ Department of Public Health Dentistry, Asan Memorial Dental College and Hospital, Chengalpattu, Tamil Nadu, India

Corresponding Author: Prabhu Subramani, Department of Public Health Dentistry, Asan Memorial Dental College and Hospital, Chengalpattu, Tamil Nadu, India, Phone: +91 9080756119, e-mail: prabhu.dent@gmail.com

How to cite this article: Subramani P, Mageswari G, Kamalini N, Muthavi M. Are E-learning Apps Replacing the Classroom Learning among Dental Students? A Questionnaire Survey. J Sci Den 2021;11(2):52-55.

Source of support: Nil

Conflict of interest: None
}

of students. Clinical dental concepts may be difficult for faculty members teaching in dental schools who are experienced in other content areas. Consequently, they may not be able to include relevant clinical visual aids and animations into their lectures, making lectures less engaging for students. ${ }^{6}$ This study aimed to determine how dental students perceive e-learning as having an influence on dental education.

\section{Materials and Methods}

A cross-sectional descriptive study was conducted among $N=160$ students of Asan Memorial Dental College and Hospital. Sample size was estimated using Epi Info based on the study conducted by Turkyilmaz et al. ${ }^{2}$ Prior to the start of the study, approval is being obtained from Institutional Scientific Review Board Asan Memorial Dental College and Hospital. Students using either smart phone or personal computers to access virtual learning were included in

() The Author(s). 2021 Open Access This article is distributed under the terms of the Creative Commons Attribution 4.0 International License (https://creativecommons. org/licenses/by-nc/4.0/), which permits unrestricted use, distribution, and non-commercial reproduction in any medium, provided you give appropriate credit to the original author(s) and the source, provide a link to the Creative Commons license, and indicate if changes were made. The Creative Commons Public Domain Dedication waiver (http://creativecommons.org/publicdomain/zero/1.0/) applies to the data made available in this article, unless otherwise stated. 
the study. Students without access to e-learning and who were not interested to participate in the study were excluded.

Survey instrument consists of a self-administered validated questionnaire, which consists of data on demographic profile followed by questions to access their knowledge, attitude, and practice toward e-learning methodologies. The questionnaire was distributed to the study participants in their classrooms, and it was collected with the help of drop box placed in their classrooms. Statistical analysis is being carried out by using SPSS version 23 to compute the frequencies and to compare the perceptions toward e-learning between preclinical and clinical students using the Chi-square test.

\section{Results}

A cross-sectional questionnaire survey was conducted among students of Asan Memorial Dental College and Hospital, regarding their preference for e-learning platform and methods. $N=160$ students participated in the study, of which $n=74$ (46.3\%) were preclinical students and $n=86(53.8 \%)$ were clinical year students.

Of the 160 students who participated, $n=74$ (46.3\%) were preclinical students and $n=86(53.8 \%)$ were clinical students. The number of students preferring e-learning in Table 1 shows $n=71(44.4 \%)$ of clinical students and $n=41$ (25.6\%) of preclinical students. Showing a positive attitude toward e-learning exists among the students.

$N=70(43.7 \%)$ of students in clinical years find finding the content they need easily, whereas only $n=48(30 \%)$ of preclinical students are able to easily locate the content they need; a significant difference was observed between the students. Only $n=38$ (23.7\%) of preclinical students are able to discuss questions with colleagues, compared with $n=65$ (40.6\%) of clinical students.

Table 2 shows that there were $n=44$ (27.5\%) clinical students who were able to apply their knowledge practically, as compared to only $n=15(9.35 \%)$ preclinical students, $(p<0.05)$. A higher percentage of clinical students $n=49(30.62 \%)$ tend to seek out e-learning than that of preclinical students $n=49(30.62 \%)(p<0.05)$, because preclinical students have more theory classes.

According to Table $3, n=36$ (22.5\%) of preclinical students and $n=70(43.75 \%)$ of clinical students are satisfied with e-learning $(p<0.05)$. It is shown in Table 4 that clinical students find it easy to discuss questions with teachers using e-learning systems, but preclinical students do not, with $n=12(17.56 \%)$ compared to $n=15$ $(17.43 \%)(p<0.05) . N=21$ students $(28.3 \%)$ felt they would not be able to discuss the question with their teachers.

Results showed that e-learning was more popular with clinical year students than with preclinical students in this study.

Table 1: Attitude and practice toward e-learning among dental students

\begin{tabular}{|c|c|c|c|c|c|}
\hline \multirow[b]{3}{*}{ Question } & \multicolumn{2}{|c|}{ Preclinical year $^{*}$} & \multicolumn{2}{|c|}{ Clinical year ${ }^{*}$} & \multirow[b]{3}{*}{$p$ value $e^{*}$} \\
\hline & Yes & No & Yes & No & \\
\hline & $N(\%)$ & $N(\%)$ & $N(\%)$ & $N(\%)$ & \\
\hline Do you prefer e-learning Apps for your studies? & $41(25.6 \%)$ & $33(20.6 \%)$ & $71(44.4 \%)$ & $15(9.4 \%)$ & 0.00 \\
\hline $\begin{array}{l}\text { Does e-learning system make it easy for you to find the } \\
\text { content you need? }\end{array}$ & $48(30 \%)$ & $26(16.3 \%)$ & 70 (43.7\%) & $16(10 \%)$ & 0.02 \\
\hline $\begin{array}{l}\text { Does e-learning system make it easy for you to discuss } \\
\text { questions with your colleagues? }\end{array}$ & $38(23.7 \%)$ & $36(22.5 \%)$ & $65(40.6 \%)$ & $21(13.2 \%)$ & 0.004 \\
\hline $\begin{array}{l}\text { Does e-learning system enable you to learn the content } \\
\text { you need? }\end{array}$ & $54(33.7 \%)$ & $20(12.5 \%)$ & $73(45.6 \%)$ & $13(8.2 \%)$ & 0.048 \\
\hline $\begin{array}{l}\text { Do e-learning systems enable you to choose what you } \\
\text { want to learn? }\end{array}$ & $51(31.8 \%)$ & $23(14.4 \%)$ & $71(44.4 \%)$ & $15(9.4 \%)$ & 0.03 \\
\hline $\begin{array}{l}\text { Does the e-learning system record your learning progress } \\
\text { and performance? }\end{array}$ & $35(21.8 \%)$ & $39(24.3 \%)$ & $65(40.6 \%)$ & $21(13.2 \%)$ & 0.00 \\
\hline
\end{tabular}

Table 2: Application of e-learning among dental students

\begin{tabular}{|c|c|c|c|c|c|c|c|}
\hline \multirow[b]{2}{*}{ Question } & \multicolumn{3}{|c|}{ Preclinical $^{*}$} & \multicolumn{3}{|c|}{ Clinical $^{*}$} & \multirow[b]{2}{*}{$p$ value } \\
\hline & Yes & No & Maybe & Yes & No & Maybe & \\
\hline $\begin{array}{l}\text { Does e-learning system help } \\
\text { you to apply the knowledge } \\
\text { gained practically? }\end{array}$ & $15(9.35 \%)$ & $29(18.125 \%)$ & $30(18.75 \%)$ & $44(27.5 \%)$ & $18(11.25 \%)$ & $24(15 \%)$ & $0.00^{*}$ \\
\hline $\begin{array}{l}\text { Does e-learning system } \\
\text { provide up-to-date content? }\end{array}$ & $37(23.12 \%)$ & 11 (6.87\%) & $26(16.25 \%)$ & 55 (34.37\%) & $8(5 \%)$ & $23(14.37 \%)$ & 0.19 \\
\hline $\begin{array}{l}\text { Do you enjoy using the } \\
\text { e-learning bv system to learn? }\end{array}$ & 27 (16.87\%) & $22(13.75)$ & 25 (15.625\%) & 49 (30.62\%) & 7 (4.3\%) & 30 (18.75\%) & $0.001^{*}$ \\
\hline $\begin{array}{l}\text { Would you recommend this } \\
\text { e-learning system to others? }\end{array}$ & 27 (16.87\%) & $17(10.62 \%)$ & $30(18.75 \%)$ & 49 (30.625\%) & $12(7.5 \%)$ & $25(15.62 \%)$ & $0.03^{*}$ \\
\hline $\begin{array}{l}\text { As a whole, do you think } \\
\text { e-learning system will be } \\
\text { successful? }\end{array}$ & $23(14.37 \%)$ & $21(13.12 \%)$ & $30(18.75 \%)$ & 39 (24.37\%) & $6(3.75 \%)$ & 41 (25.625\%) & $0.001^{*}$ \\
\hline
\end{tabular}


Table 3: Overall perception about e-learning

\begin{tabular}{lllc}
\hline Year & Stressed & Satisfied & $p$ value \\
\hline Preclinical $^{*}$ & $38(23.75 \%)$ & $36(22.5 \%)$ & $0.00^{*}$ \\
Clinical $^{*}$ & $16(10 \%)$ & $70(43.75 \%)$ & \\
\hline
\end{tabular}

${ }^{*}$ Chi-square test, $(p<0.05$-statistically significant)

Table 4: Discussion of e-learning subjects with their teachers

\begin{tabular}{lcccccc}
\hline \multicolumn{6}{l}{ The e-learning system makes it easy for you to discuss questions with your teachers } \\
\hline Year & Strongly disagree & Disagree & Neutral & Agree & Strongly agree & pvalue \\
\hline Preclinical $^{*}$ & $4(5.4 \%)$ & $17(22.9 \%)$ & $40(54.05 \%)$ & $11(14.86)$ & $2(2.70 \%)$ & $0.04^{*}$ \\
Clinical $^{*}$ & $5(5.81 \%)$ & $6(6.97 \%)$ & $60(69.76 \%)$ & $10(11.62 \%)$ & $5(5.81 \%)$ & \\
\hline
\end{tabular}

${ }^{*}$ Chi-square test, $(p<0.05$-statistically significant)

\section{Discussion}

Various studies have been accomplished to help students switch from the traditional method of learning to e-learning. Most dental schools are forced to shift to e-learning for the safety of students in this global pandemic. Mobile phones are the most popular devices for e-learning applications. During dental practices, dental students are easily exposed to saliva and blood, putting them at risk for Corona virus infection. Moreover, tooth preparation and ultrasound cleaning can create aerosols that can spread viruses. Since aerosols can remain airborne for a long time, they may pose a respiratory infection risk to clinical teachers and dental students. Thus, online dental teaching seems to be a reasonable option to prevent the spread of COVID-19 among students. Due to the rapid advancement of technology, smart devices such as mobile phones, tablets, and laptops make it convenient for students to listen to classes and contact teachers. ${ }^{7}$

According to Aber et al., dental students tend to be positive about online learning and that online learning was useful, but they really wanted face-to-face instruction and more practical experience as they want to gain cognitive skills. We agree with this assertion because in our study, only $n=44(27.5 \%)$ of clinical students and $n=15(9.37 \%)$ of preclinical students gained knowledge that could be applied practically. ${ }^{8}$

In a study performed by Sahar et al., it was found that most of the students during a pandemic time were out of sources for studying since there is no classroom learning. The study concluded that both positive and negative responses were equally expressed toward e-learning. Comparing our study with the study by Sahar et al., $n=70$ (81.39\%) of clinical students and $n=36$ (48.54\%) of preclinical students were satisfied with e learning, and $n=38$ $(45.35 \%)$ of preclinical students were feeling stressed from e-learning studies. ${ }^{9}$

According to Peter et al., $n=50$ (35.46\%) of dental students accepted e-learning for study. On comparable to our sample, $n=41$ (25.46\%) of preclinical students preferred e-learning and $n=71$ (44.4\%) of clinical students preferred e-learning, confirming our findings. ${ }^{10}$

According to Rupandeep et al. $n=488(30 \%)$ of preclinical students and $n=1085$ (69\%) of clinical students find the content on internet is up-to-date, on comparing with our study $n=37$ (23.12\%) of preclinical students, and $n=55$ (34.37\%) agreed that they can find up-to-date content on e-learning app. $N=752$ (30.3\%) of preclinical students and $n=1501$ (69.7\%) of clinical students agreed that they have reduced communication with instructor, whereas in our study, $n=21$ (28.3\%) of preclinical students and $n=11$ (12.78\%) of clinical students disagreed on discussion of e-learning topic with their teachers.

Although both studies have shown a huge interest in e-learning, Rupandeep et al.'s study had a higher percentage of results. Once the college reopened, we began the study. Eventually, the students started coming back to college and started taking traditional theory classes for learning. The reason for the huge difference in results compared to the Rupandeep et al.'s study is due to this fact.

Learning case studies, quizzes, and discussion through virtual learning lead to improved learning performance in students. ${ }^{11}$ Kazi et al. conducted the study to assess the Google classroom sessions on 2nd-year students. Forty-seven (56\%) students responded that they can able to clear the doubts with the faculty. On comparing with our study, 13 (17.56\%) of preclinical students and 15 (17.43\%) of clinical students responded the same. The study conducted by Kazi et al. supports our study. There is a big difference between our study's results and those of Kazi et al.: their study focused only on assignment completion, and ours focused on overall learning.

Various studies conducted worldwide show that e-learning showed it increases the learning ability of students. It improved the vocabulary of students. However, there exists a knowledge gap between online vs traditional learning but they are not sure that they can retain the knowledge gained from online learning. ${ }^{12}$ However, dental and medical students must take more practical classes in order to grasp the subject as its intended.

\section{ConClusion}

Learning through electronic means is not only a change in technology. It represents a redefinition of how we pass on information, skills, and values to younger generations of workers and students. In conclusion, e-learning apps are more beneficial for dental students than traditional methods of learning. The future of dental education will be made up of a combination of physical classes and online classes, which is known as blended learning.

\section{References}

1. Iqbal S. Perceptions of undergraduate dental students towards e-learning in Lahore Medical and Dental College. Pak J Med Health Sci 2016;10(4):1191-1193. Available from: https://www.pjmhsonline. com/2016/oct_dec/pdf/1191.pdf

2. Turkyilmaz I, Hariri NH, Jahangiri L. Student's perception of the impact of e-learning on dental education. J Contemp Dent Pract 2019;20(5):616-621. PMID: 31316028.

3. Dalmolin A. Learning style preference and e-learning experience of undergraduate dental students. Rev Odontol UNESP 2018;47(3): 175-182. DOI: 10.1590/1807-2577.05118. 
4. Ariana A. Integration of traditional e-learning methods to improve learning outcomes for dental students in histopathology. J Dent Educ 2016;80(9):1140-1148. PMID: 27587581.

5. Asiry M. Dental student's perceptions of an online learning. Saudi Dent J 2017;29(4):167-170. DOI: 10.1016/j.sdentj.2017.03.005.

6. Jayasinghe R. Srilankan dental students perspective on effectiveness of e-learning. Asia Pac Scholar 2021;6(4):7-16. DOI: 10.29060/ TAPS.2022-7-1/OA2415.

7. Jiang Z. Online dental teaching practices during CoVID-19 pandemic: cross sectional online survey from china. BMC Oral Health 2021;21(189):1-9. DOI: 10.1186/s12903-021-01547-7.

8. Gawish A. Attitude and perception of Egyptian undergraduate dental students to e-learning during covid 19 at North Sinai Egypt. Genesis 2021;2(2):1-15. Available from: https://www.genesispub.org/ resource/images/articles/pdf150.pdf
9. Abbasi S. Perceptions of students regarding elearning during covid 19 at a private medical college. Pak J Med Sci 2020;36 (COVID 19-S4):57-61. DOI: 10.12669/pjms.36.COVID19-S4.2766.

10. Schulz P. Acceptance of e-learning devices by dental students. J Med Internet Res 2013;2(2):e6. DOI: 10.2196/med20.2767.

11. Samra R. Dental students' Perception on the impact of E-learning in continuing dental education during the current pandemic scenario. Indian J Dent Sci 2021;13(2):61-72. DOI: 10.4103/ijds.ijds_14_21.

12. Mukhit M. Google Classroom sessions as a modern e-learning tool for the second year undergraduate dental students - a questionnaire feedback study. Int J Med Sci Public Health 2020;9(7):1-6. DOI: 10.5455/ijmsph.2020.06104202008072020. 